\title{
Article \\ Carbon Black Replacement in Natural Rubber Composites Using Dry-Milled Calcium Carbonate, Soy Protein, and Biochar
}

\author{
Steven C. Peterson $(\mathbb{D}$
}

check for updates

Citation: Peterson, S.C. Carbon Black Replacement in Natural Rubber Composites Using Dry-Milled Calcium Carbonate, Soy Protein, and Biochar. Processes 2022, 10, 123. https://doi.org/10.3390/pr10010123

Academic Editors: Mattia Bartoli and Luca Lavagna

Received: 24 August 2021

Accepted: 5 January 2022

Published: 7 January 2022

Publisher's Note: MDPI stays neutral with regard to jurisdictional claims in published maps and institutional affiliations.

Copyright: (C) 2022 by the author. Licensee MDPI, Basel, Switzerland. This article is an open access article distributed under the terms and conditions of the Creative Commons Attribution (CC BY) license (https:// creativecommons.org/licenses/by/ $4.0 /)$
Plant Polymer Research, National Center for Agricultural Utilization Research, Agricultural Research Service, USDA, 1815 N. University Ave, Peoria, IL 61604, USA; Steve.Peterson@usda.gov

\begin{abstract}
Recent discoveries have shown that calcium carbonate and soy protein interactions can be used to reinforce rubber composites with improvements on the effective crosslink density and moduli. However, the method to incorporate the soy protein into the rubber matrix may be costly to scale up, since it involves microfluidization and drying steps prior to rubber compounding. In this work, a simpler process involving dry-milled calcium carbonate and soy protein was used to explore filler blends of calcium carbonate, soy protein, biochar, and carbon black. By blending these filler materials in various ratios, rubber composite samples with $40-50 \%$ of the carbon black replaced by sustainable alternatives were made. These composites had essentially the same tensile strength, with better toughness and elongation properties relative to the carbon black control. These composites would reduce dependence on petroleum and be more amenable to the rubber composite compounding infrastructure.
\end{abstract}

Keywords: calcium carbonate; soy protein; Paulownia; biochar; carbon black; natural rubber

\section{Introduction}

Carbon black (CB) has long been the standard filler for the tire industry due to its high purity and excellent reinforcement properties [1,2]. However, there are several reasons that renewable alternatives to $C B$ need to be developed; (1) the fossil fuels that enable the manufacture of $C B$ are finite [3], (2) the cost of fossil fuels is volatile and can be affected sharply by unpredictable geopolitical conditions [4], and (3) reducing CB usage and production helps improve the atmosphere [5].

Biochar is a solid carbon source made from biomass. It is produced by treating the biomass at high temperature in an oxygen-free atmosphere; this process is known as pyrolysis [6]. Because virtually all biomass contains carbon, the possibilities for sustainable biochar feedstocks are endless. However, the trade-off is lack of purity. Biomass is far more heterogeneous than petroleum in terms of carbon content and will introduce ash from inherent inorganic components. Biochar with high carbon content and low ash content is possible to make, although it takes special care and attention in the pyrolysis processing of the feedstock [7]. By studying many different biochar feedstock sources in our laboratory, we have determined that biochars made from trees, particularly hardwoods, tend to have better carbon and ash content than other low-value renewable feedstock candidates such as grasses, corncobs, or manures [8-11].

Particle size is another problem when using biochar to replace CB because biochar is sourced from pyrolyzing biomass. Biochar's initial size is similar to the morphology of the feedstock and so it must be milled or ground, which becomes expensive or impossible as the target particle size approaches the nm range. This challenge was seen in previous work in our laboratory [12,13], when the biochar had a small but significant population of particles ranging from 10-100 microns. Even though the number of these larger particles was small compared to the rest of the distribution, they caused problems due to localized stresses in the rubber composite, leading to fracture [14]. To improve this process, we have used the silica milling technique [15], which helps break down larger biochar particles. 
One rapidly growing hardwood is Paulownia elongata [16]. It can be coppiced, i.e., wood that is cut from the tree is regrown and harvested repeatedly, taking much less space than trees that are only harvested after a single cut. Studies of Paulownia plantations in the southern United States have shown its high-yielding potential. One plantation with a density of $\sim 1700$ trees per hectare had a biomass production of over 80 tons in under four years [17], and another slightly denser plantation produced over 250 tons six years after planting [18]. Paulownia flourishes in a range of hardiness zones (6-11) [19], giving it a large potential area of essentially the entire southeastern United States. Paulownia is a popular biomass feedstock with applications such as bioethanol production [20] and wood plastic composite filler [21]. Paulownia biochar can also be used as a horticultural amendment to soil [22].

Our laboratory has focused on replacing carbon black with biochar for many years now, and it seems that the practical limits we have been able to achieve while not sacrificing tensile strength or elongational properties are between $40-50 \%$ replacement. However, new reinforcement techniques may help improve this replacement ratio. In a recent study [23], Jong discovered an effective cooperative reinforcement technique utilizing calcium carbonate and soy protein for natural rubber composites. The soy protein increases the degree of crosslinking in the calcium carbonate-reinforced rubber, thus increasing the modulus as well. It was also discovered that the reinforcement could be improved by using stearic acid-coated calcium carbonate (SA-CC), due to its more hydrophobic nature and improved van der Waals interactions with the rubber matrix. In Jong's original study [23], the soy protein was incorporated into a rubber latex via an aqueous dispersion that was hydrolyzed and then microfluidized to reduce the size of the soy protein particles. This mixture was then freeze-dried (other ways of drying would also be acceptable) before being compounded with the SA-CC and other standard rubber chemicals in a Brabender mixer, then compression molded into rubber composite samples.

In the current work, our goal was to explore a simpler process of using a planetary ball mill to combine SA-CC with powdered soy protein, then take this dry mixture and combine it with silica-milled biochar made from Paulownia feedstock to create a filler substitute for $\mathrm{CB}$ in natural rubber (NR) composites. This mixture could then be compounded with slab rubber in a Brabender mixer to make rubber composite samples. This process would be more amenable to traditional rubber processing and its infrastructure because it uses only dry components and would eliminate hydrolysis, microfluidization, and freeze-drying (or any other necessary drying method) steps that may prove costly. Rubber composites made using this simpler process were compared to the CB-filled control to see how much CB could be replaced with the SA-CC/soy protein/biochar filler while having similar tensile properties. Varying ratios of SA-CC, soy protein, and biochar were also examined to optimize the tensile properties of the composites.

\section{Materials and Methods}

\subsection{Materials Used}

SA-CC nanoparticles were purchased from US Research Nanomaterials, Inc. (Houston, TX, USA). Paulownia elongata biochar was obtained from Biochar Options (Whitewater, WI, USA). Ardex F brand soy protein isolate was obtained from Archer-Daniels-Midland Company (Chicago, IL, USA). N-339 grade carbon black (Vulcan M) was provided by the Cabot Corporation (Alpharetta, GA, USA). TSR-grade natural slab rubber was supplied by Michelin (Greenville, SC, USA). Silica-milling techniques utilized Agilon 400GD nanosilica obtained from PPG Industries (Pittsburgh, PA, USA).

\subsection{Chemical and Physical Material Properties}

Ash content and elemental analysis of carbon, hydrogen, nitrogen, and oxygen were carried out as detailed in a previous manuscript [24]. SA-CC density was supplied by the manufacturer. Biochar and soy protein absolute densities were measured as detailed in a 
previous manuscript [13]. XRD spectra of biochar, $\mathrm{CB}$, and soy protein were gathered as detailed in a previous manuscript [25].

Scanning electron microscopy (SEM) was performed using a JEOL JSM-6010A (JEOL Inc., Peabody, MA, USA). Rubber composite samples were mounted on SEM stubs to obtain images of the fractured surface following Instron testing. Stubs were coated with gold using an SPI sputter coater (Structure Probe Inc., West Chester, PA, USA).

\subsection{Milling Procedure}

Paulownia biochar was silica-milled using a prior technique [24]. Mixtures of SA-CC and soy protein with different ratios (20:80, 40:60, 60:40, and 80:20) were milled as follows using an SFM-1 (model QM-3SP2) planetary ball mill (MTI Corporation, Richmond, CA, USA) with $500 \mathrm{~mL}$ stainless steel milling jars and lids. Milling media were $3 \mathrm{~mm}$-diameter yttrium-stabilized zirconia spheres (Inframat Corporation, Manchester, CT, USA). In each milling jar an appropriate weight ratio of SA-CC and soy protein totaling $40 \mathrm{~g}$ was added, followed by $950 \mathrm{~g}$ of milling media. The jars were loaded into the mill and run for a total of $36 \mathrm{~min}$ (18 $\mathrm{min}$ in one direction, followed by a $6 \mathrm{~min}$ rest period, followed by $18 \mathrm{~min}$ in the opposite direction) at $500 \mathrm{rpm}$. The sample jars were allowed to cool to room temperature. The milled SA-CC/soy protein powder at various ratios were then collected and ready to use as compounding ingredients.

\subsection{Formation of Rubber Composites and Tensile Testing}

Rubber composites used a similar masterbatch to a previous natural rubber study [25] with the following differences: (1) all composite samples were approximately $43 \mathrm{phr}$ (30\% by weight) total filler, and (2) the filler mixture for the current work was $\mathrm{CB}$ and/or biochar/SA-CC/soy protein. Table 1 shows the phr amounts for all ingredients of the composites used in the current work.

Table 1. The 30\% total filler control and composite formulations (phr).

\begin{tabular}{|c|c|c|c|c|c|c|c|c|c|c|}
\hline Filler Composition & NR & TMQ & 6PPD & BC & CC-SP & CB & Stearic Acid & $\mathrm{ZnO}$ & Sulfur & CBTS \\
\hline unfilled NR & 100 & 0.50 & 0.50 & 0 & 0 & 0 & 2.00 & 5.00 & 2.50 & 1.00 \\
\hline $100 \%$ CB (control) & 100 & 0.50 & 0.50 & 0 & 0 & 42.85 & 2.00 & 5.00 & 2.50 & 1.00 \\
\hline 100:0:0 BC/CC-SP/CB & 100 & 0.50 & 0.50 & 42.85 & 0 & 0 & 2.00 & 5.00 & 2.50 & 1.00 \\
\hline 60:20:20 BC/CC-SP/CB & 100 & 0.50 & 0.50 & 25.71 & 8.57 & 8.57 & 2.00 & 5.00 & 2.50 & 1.00 \\
\hline 20:60:20 BC/CC-SP/CB & 100 & 0.50 & 0.50 & 8.57 & 25.71 & 8.57 & 2.00 & 5.00 & 2.50 & 1.00 \\
\hline 30:50:20 BC/CC-SP/CB & 100 & 0.50 & 0.50 & 12.86 & 21.43 & 8.57 & 2.00 & 5.00 & 2.50 & 1.00 \\
\hline 33:33:34 BC/CC-SP/CB & 100 & 0.50 & 0.50 & 14.14 & 14.14 & 14.57 & 2.00 & 5.00 & 2.50 & 1.00 \\
\hline 0:60:40 BC/CC-SP/CB & 100 & 0.50 & 0.50 & 0 & 25.71 & 17.14 & 2.00 & 5.00 & 2.50 & 1.00 \\
\hline 12:48:40 BC/CC-SP/CB & 100 & 0.50 & 0.50 & 5.14 & 20.57 & 17.14 & 2.00 & 5.00 & 2.50 & 1.00 \\
\hline 0:50:50 BC/CC-SP/CB & 100 & 0.50 & 0.50 & 0 & 21.43 & 21.43 & 2.00 & 5.00 & 2.50 & 1.00 \\
\hline 10:40:50 BC/CC-SP/CB & 100 & 0.50 & 0.50 & 4.28 & 17.14 & 21.43 & 2.00 & 5.00 & 2.50 & 1.00 \\
\hline 20:30:50 BC/CC-SP/CB & 100 & 0.50 & 0.50 & 8.57 & 12.86 & 21.43 & 2.00 & 5.00 & 2.50 & 1.00 \\
\hline 0:40:60 BC/CC-SP/CB & 100 & 0.50 & 0.50 & 0 & 17.14 & 25.71 & 2.00 & 5.00 & 2.50 & 1.00 \\
\hline 8:32:60 BC/CC-SP/CB & 100 & 0.50 & 0.50 & 3.43 & 13.71 & 25.71 & 2.00 & 5.00 & 2.50 & 1.00 \\
\hline
\end{tabular}

NR: natural rubber; TMQ: 2,2,4-trimethyl-1,2-dihydroquinone; 6PPD: $N$-1,3-dimethylbutyl- $N$-phenyl-p-phenylene diamine; BC: biochar; CC-SP: $60 \%$ stearic acid-coated calcium carbonate/40\% soy protein; CB: carbon black; $\mathrm{ZnO}$ : zinc oxide; CBTS: $N$-cyclohexyl-2-benzothiazolesulfenamide.

Tensile property testing and statistical analysis were performed on an Instron 55R1123C 5420 (Instron, Inc., Norwood, MA, USA) using Bluehill Software version 3.61. For tensile tests, at least five replicates of each composite sample were run.

\subsection{Thermal Stability}

Thermogravimetric analysis (TGA) was performed using a TA Instruments Q500 TGA (New Castle, DE, USA). A small piece (10-15 mg) was cut from the rubber composite sample and weighed in an open, tared platinum TGA pan. After loading, each sample was heated from room temperature to $800^{\circ} \mathrm{C}$ at a heating rate of $20^{\circ} \mathrm{C} / \mathrm{min}$ in an air atmosphere 
(60 mL/min). Analysis of results were completed using TA Instruments' Universal Analysis 2000 software (Version 4.5a).

\section{Results and Discussion}

\subsection{Chemical and Physical Characterization}

Paulownia biochar was measured and found to be $(95.2 \pm 0.7) \%$ carbon, $(1.4 \pm 0.3) \%$ hydrogen, $(2.5 \pm 0.8) \%$ ash, and $(0.91 \pm 0.7) \%$ oxygen (by difference). Only trace amounts of nitrogen were present. The densities of Paulownia biochar, SA-CC, and soy protein were $1.76,2.93$, and $1.33 \mathrm{~g} / \mathrm{cm}^{3}$, respectively. In a previous work [24], FTIR analysis of this particular Paulownia biochar did not show any significant functional groups present, consistent with a biochar that is $>95 \%$ carbon. Figure 1 shows SEM images of Paulownia biochar, SA-CC, and soy protein. Since Paulownia biochar is milled from the pyrolyzed wood feedstock, it has a pulverized appearance that looks inherently different to SA-CC and soy protein. SA-CC was listed by the manufacturer to have a particle size of $50 \mathrm{~nm}$, but since SA-CC was imaged as a dry powder, it underwent aggregation because its adhesion forces are much stronger than gravitational forces [26]. Figure 2 shows the $X R D$ results for $C B$, soy protein, and Paulownia biochar. Carbon black-like materials have a graphitic structure with characteristic peaks near 24 and $43^{\circ} 2 \theta$ [27], and these can be seen by both the carbon black and biochar used in this work. There are no sharp peaks indicating any other crystalline structure (i.e., impurities), consistent with biochar of this carbon content. Soy protein shows the typical $\alpha$-helix and $\beta$-sheet peaks present at 10 and $20^{\circ} 2 \theta$ [28], respectively. The fact that these three filler materials do not show any sharp peaks indicates that there is very little crystalline domain present in these fillers, and they are primarily amorphous.

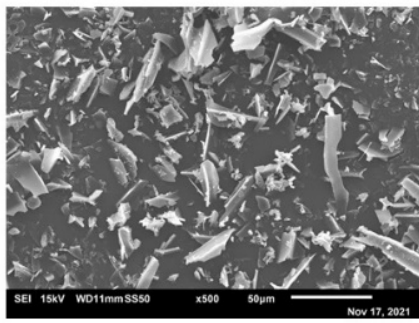

Paulownia biochar

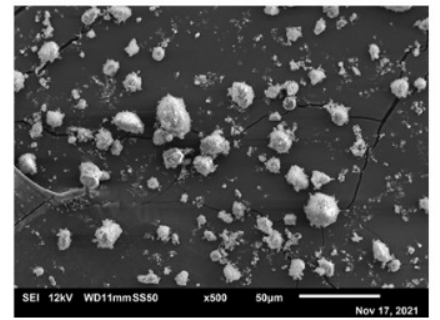

SA-CC

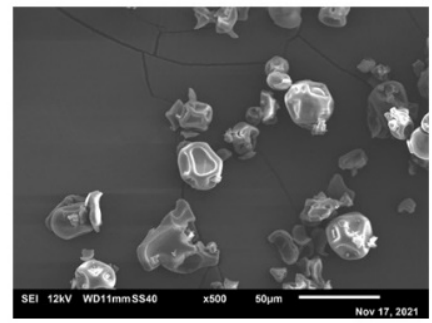

soy protein

Figure 1. SEM images at $500 \times$ of the three fillers used in this work. The small white bar in the lower right section of each SEM image represents 50 microns.

\subsection{Determining $S A-C C / S o y$ Protein Ratio}

In Jong's study [23] on which this work was based, the author describes a synergistic effect between SA-CC, soy protein, and natural rubber. Soy protein interacts with natural rubber, but SA-CC reduces this effect. Soy-protein-reinforced natural rubber tends to have higher modulus and lower elongation at break, while SA-CC-reinforced natural rubber has greater tensile strength and elongation, but lower modulus. By varying the ratios of these two components, the low modulus inherent in SA-CC reinforcement can be improved by soy protein, and tensile strength, modulus, and elongation can be optimized. In Jong's work, it was found that the optimal SA-CC: soy protein ratio for reinforcement was 40:60, but with the changes in processing methods examined in this work, various SA-CC: soy protein ratios were tested to optimize for dry milling conditions. No biochar or CB was used as filler for this determination. Results can be seen in Table 2. The SA-CC: soy protein ratio of 60:40 yielded the highest tensile strength and toughness; therefore, this ratio was chosen as representative to be mixed with biochar and CB in subsequent experiments. 


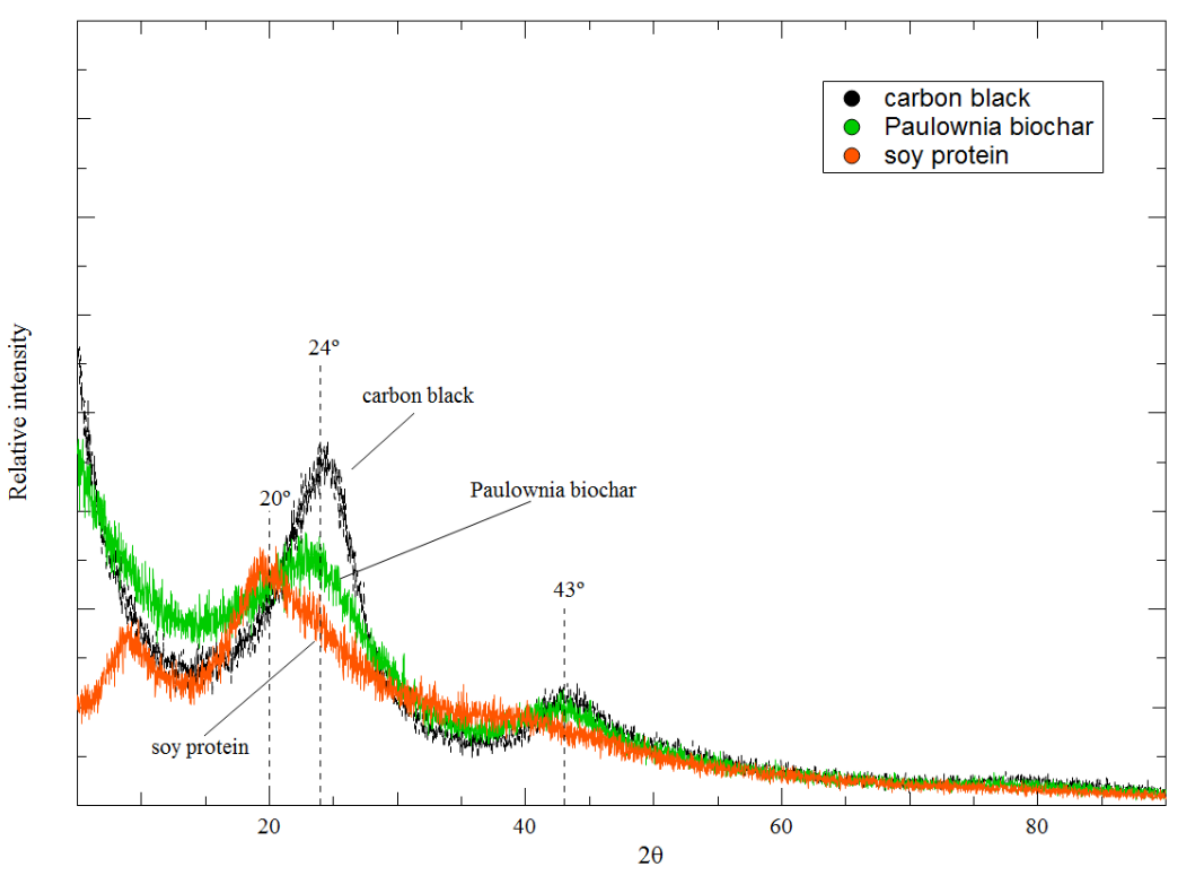

Figure 2. X-ray diffraction traces of the Paulownia biochar, carbon black, and soy protein. Graphitic d-spacing peaks typical of carbon black-type structure are visible at $24^{\circ}$ and $43^{\circ} 2 \theta$, and the soy protein $\alpha$-helix and $\beta$-sheet peaks at 10 and $20^{\circ} 2 \theta$ are also visible.

Table 2. SA-CC/soy protein ratio comparison.

\begin{tabular}{ccccc}
\hline SA-CC/Soy Protein Ratio & Tensile Strength (MPa) & Elongation (\%) & Toughness (MPa) & Young's Modulus (MPa) \\
\hline $20: 80$ & $15.3 \pm 1.3$ & $631 \pm 20$ & $31.2 \pm 2.8$ & $1.8 \pm 0.2$ \\
$40: 60$ & $19.4 \pm 0.5$ & $656 \pm 5$ & $39.2 \pm 0.9$ & $1.9 \pm 0.1$ \\
$60: 40$ & $20.2 \pm 0.7$ & $682 \pm 5$ & $40.0 \pm 1.4$ & $1.8 \pm 0.3$ \\
$80: 20$ & $18.7 \pm 1.2$ & $699 \pm 17$ & $36.0 \pm 2.3$ & $1.6 \pm 0.4$ \\
\hline
\end{tabular}

SA-CC: stearic acid-coated calcium carbonate.

\subsection{Silica Milling Method}

Silica milling is a dry-milling method used to reduce the particle size of biochar [7,15]; it is convenient because a small amount ( $1 \%$ by weight) can significantly reduce the population of biochar particles greater than 10 microns. Biochar particles of this size and larger can greatly weaken rubber composites by causing localized stresses and fracture points within the rubber matrix [14]. The effects of silica milling are shown in Figure 3. The stress-strain curves show a CB-filled control (A), along with two $100 \%$ biochar-filled composites, with the only difference between them being one is silica-milled (B) and the other is not (C). Additionally included are corresponding SEM images of the fractured surface of these three samples. Biochar particles that have been silica-milled are clearly smaller, with fewer particles $>10$ microns, and this is reflected in their increased stress and strain relative to the sample with no silica. Silica-milled biochar was therefore used in all optimization trials to replace the maximum amount of $\mathrm{CB}$. 

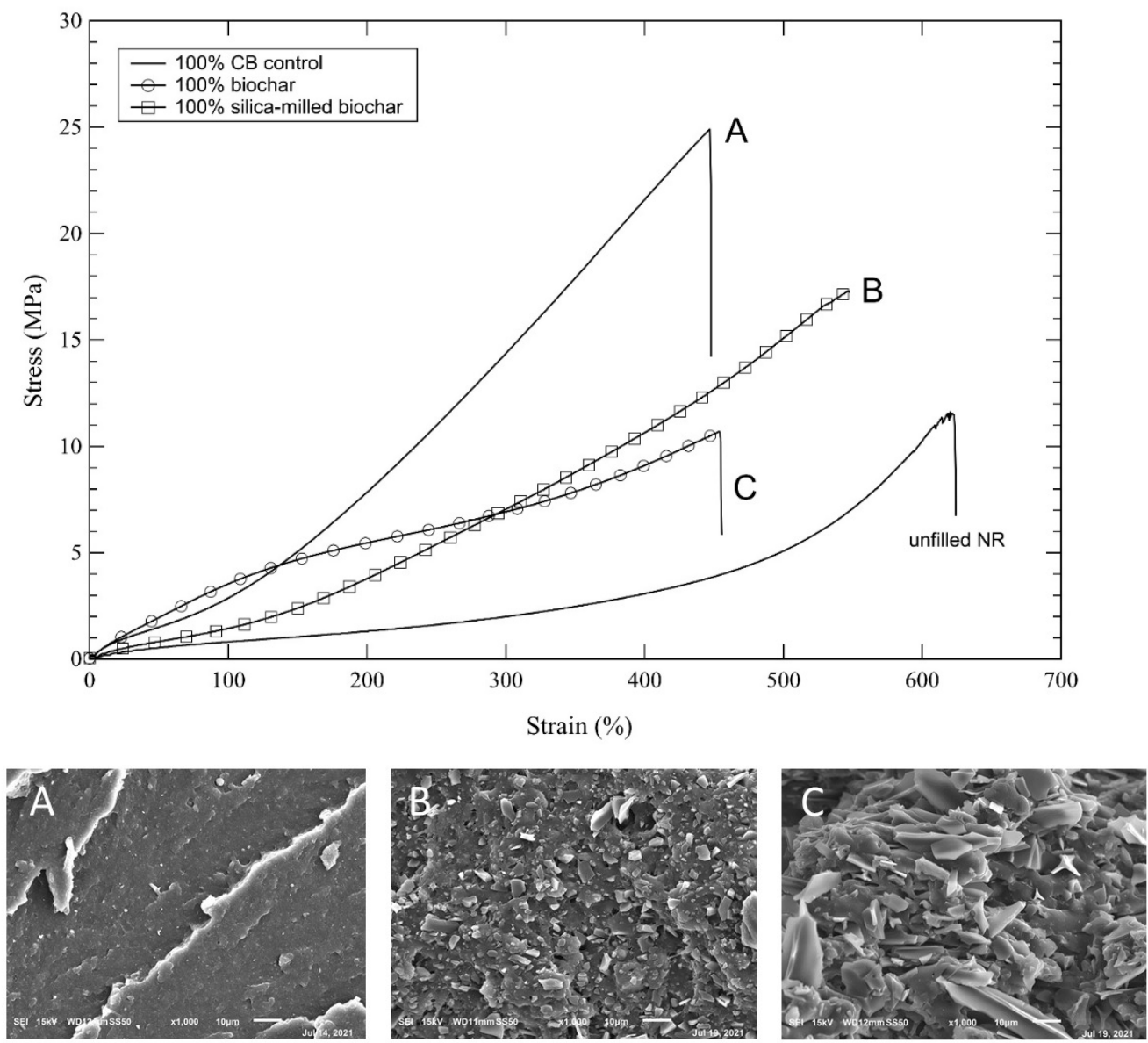

Figure 3. Tensile properties for: (A) 100\% CB filled control, (B) 100\% silica-milled biochar, and (C) $100 \%$ biochar with no silica. Images $(\mathbf{A}-\mathbf{C})$ are SEM images at $1000 \times$ of the three composite samples along their fractured surface after tensile testing. The small white bar in the lower right section of each SEM image represents 10 microns.

\subsection{Replacement of Carbon Black with Biochar, SA-CC, and Soy Protein}

A total filler concentration of $30 \%$ was chosen in order to compare this study with previous CB replacement studies [7] that had also been run at 30\% total filler. Results of these trials can be seen in Table 3, in which the treatments are listed in descending order of percent $\mathrm{CB}$ replaced, with the $\mathrm{CB}$ control listed first.

Table 3. Tensile properties of rubber composite samples.

\begin{tabular}{|c|c|c|c|c|c|c|}
\hline Filler Description & $n$ & \% CB Replaced & $\begin{array}{c}\text { Tensile Strength } \\
\text { (MPa) }\end{array}$ & Elongation (\%) & Toughness (MPa) & $\begin{array}{l}\text { Young's Modulus } \\
\text { (MPa) }\end{array}$ \\
\hline $100 \%$ CB control & 6 & 0 & $25.1 \pm 0.6$ & $451 \pm 9$ & $47.8 \pm 2.3$ & $4.3 \pm 0.5$ \\
\hline $100 \%$ biochar control & 6 & 100 & $17.8 \pm 0.9$ & $547 \pm 13$ & $39.1 \pm 2.8$ & $2.0 \pm 0.2$ \\
\hline 20:60:20 BC/CC-SP/CB & 6 & 80 & $20.9 \pm 0.6$ & $621 \pm 8$ & $44.3 \pm 1.5$ & $2.1 \pm 0.3$ \\
\hline 30:50:20 BC/CC-SP/CB & 6 & 80 & $20.7 \pm 1.1$ & $611 \pm 13$ & $44.1 \pm 2.9$ & $2.3 \pm 0.3$ \\
\hline 60:20:20 BC/CC-SP/CB & 8 & 80 & $19.8 \pm 0.9$ & $571 \pm 19$ & $43.4 \pm 1.6$ & $2.2 \pm 0.2$ \\
\hline 33:33:34 BC/CC-SP/CB & 6 & 66 & $21.9 \pm 0.7$ & $591 \pm 8$ & $47.5 \pm 1.4$ & $2.3 \pm 0.1$ \\
\hline 12:48:40 BC/CC-SP/CB & 5 & 60 & $22.7 \pm 0.5$ & $594 \pm 9$ & $48.1 \pm 2.0$ & $2.4 \pm 0.4$ \\
\hline 0:60:40 BC/CC-SP/CB & 6 & 60 & $21.4 \pm 0.8$ & $594 \pm 12$ & $43.9 \pm 2.1$ & $2.4 \pm 0.3$ \\
\hline 10:40:50 BC/CC-SP/CB & 6 & 50 & $24.1 \pm 0.4$ & $594 \pm 11$ & $52.0 \pm 1.6$ & $2.5 \pm 0.3$ \\
\hline 20:30:50 BC/CC-SP/CB & 6 & 50 & $23.8 \pm 0.8$ & $581 \pm 9$ & $51.5 \pm 2.2$ & $2.5 \pm 0.3$ \\
\hline 0:50:50 BC/CC-SP/CB & 6 & 50 & $22.3 \pm 1.4$ & $593 \pm 19$ & $47.9 \pm 4.8$ & $2.3 \pm 0.5$ \\
\hline 8:32:60 BC/CC-SP/CB & 5 & 40 & $24.9 \pm 0.9$ & $571 \pm 2$ & $54.0 \pm 2.2$ & $3.0 \pm 0.2$ \\
\hline 0:40:60 BC/CC-SP/CB & 5 & 40 & $22.6 \pm 0.3$ & $535 \pm 6$ & $46.0 \pm 1.2$ & $3.1 \pm 0.3$ \\
\hline
\end{tabular}

$n$ : number of replicates; CB: carbon black; BC: biochar; CC-SP: $60 \%$ stearic acid-coated calcium carbonate $/ 40 \%$ soy protein. 
In general terms, as the percentage of $\mathrm{CB}$ replaced decreases, tensile strength increases. The filler combination of biochar, SA-CC, and soy protein, at least in this dry-milling process, does not do well with matching the stiffness of the CB control, as evidenced by lower Young's modulus results across the entire collection of samples. Consequently, all the samples had higher elongational values. It was notable that for the best reinforcement effects (i.e., highest tensile strength), a small, nonzero amount of biochar was required, but increasing the biochar: CC-SP ratio did not improve the tensile strength. For samples that replaced 40 or $50 \%$ of the $\mathrm{CB}$, tensile strengths were comparable to the control, with two samples (10:40:50 and 8:32:60 BC/CC-SP/CB) overlapping the tensile strength of the CB control within experimental error. Figure 4 illustrates these stress-strain curves, and SEMs of the fractured surfaces are also included. There is no real discernible difference in the SEM images between Figure $4 B, C$, but the larger biochar particles are easier to see than the smaller, more well-dispersed CB aggregates shown in Figure 4A.
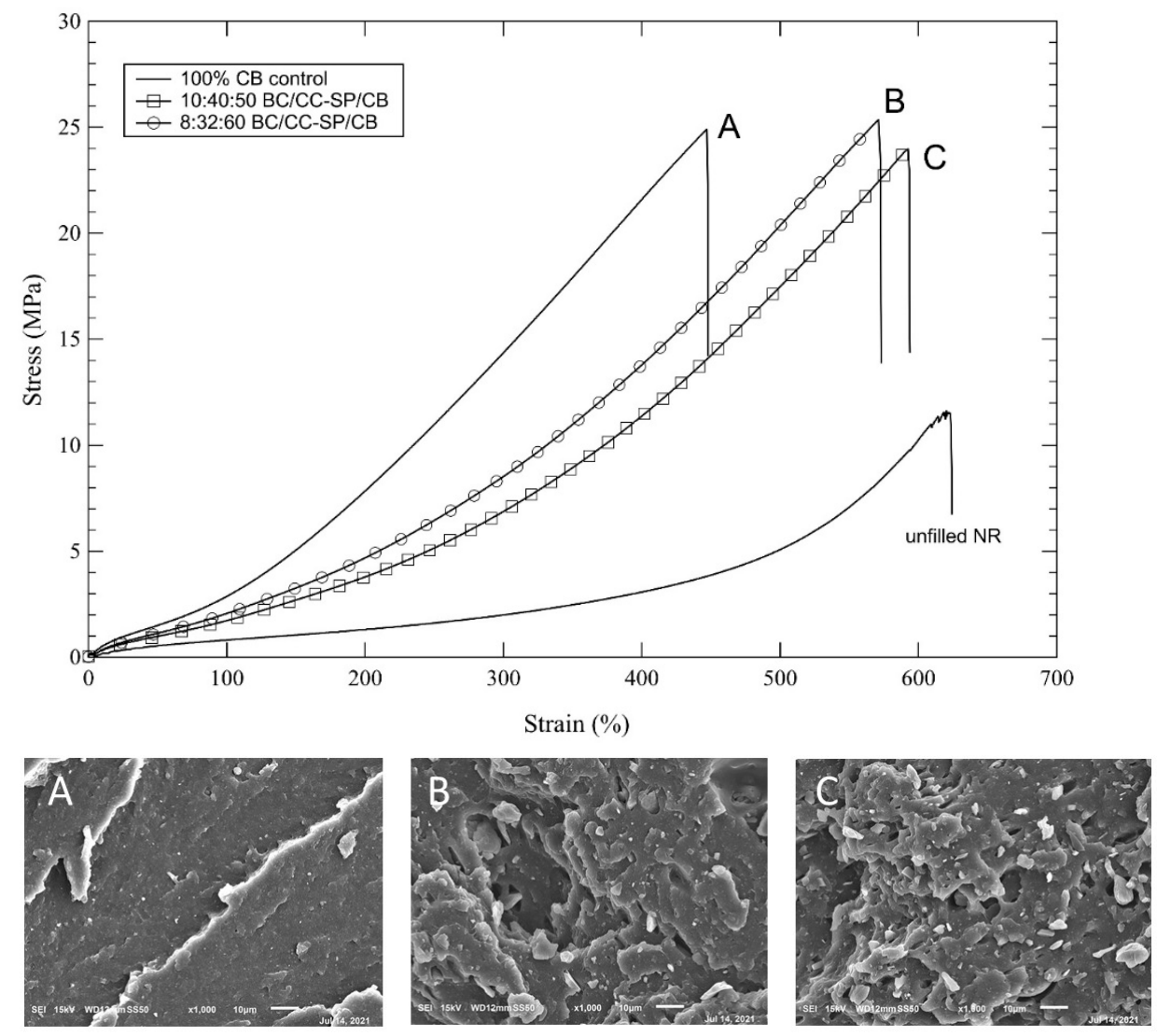

Figure 4. Tensile properties for: (A) 100\% CB filled control, (B) 8:32:60 BC/CC-SP/CB, and (C) 10:40:50 $\mathrm{BC} / \mathrm{CC}-\mathrm{SP} / \mathrm{CB}$. Additionally included are SEM images at $1000 \times$ of the three composite samples along their fractured surface after tensile testing. The small white bar in the lower right section of each SEM image represents 10 microns.

\subsection{Thermal Stability}

Thermal stability of the $100 \%$ CB control composite compared to an analogous composite filled with $100 \%$ silica-milled biochar can be seen in Figure 5A. The curves are similar until just below $500{ }^{\circ} \mathrm{C}$, where $\mathrm{CB}$ provides slightly better thermal stability. Figure $5 \mathrm{~B}$ shows the result of changing the biochar: (60/40 SA-CC/soy protein) ratio while holding CB concentration constant at $20 \%$. Changing this ratio does two things; (1) between $400-500{ }^{\circ} \mathrm{C}$, thermal stability is improved slightly as biochar concentration is increased, and (2) ash concentration, represented by the plateau region beyond $550{ }^{\circ} \mathrm{C}$, is proportional to the amount of $\mathrm{CaCO}_{3}$ in the composite. An interesting effect can be seen in Figure 5C, which is similar to Figure 5B with varying biochar: (60/40 SA-CC/soy protein) ratio, except in this plot the CB concentration 
is higher (50\%). In this plot the 20/30/50 biochar/(60-40 SA-CC-soy protein)/CB shows enhanced thermal stability from approximately 470 to $540{ }^{\circ} \mathrm{C}$, with a shape resembling the CB control. This behavior was also displayed for the 8/32/60 and 0/40/60 composite samples (not shown for clarity). The common factor in these samples was a high $(\geq 50 \%) \mathrm{CB}$ concentration coupled with a CB: $(60 / 40 \mathrm{SA}-\mathrm{CC} /$ soy protein) ratio $>1.3$.
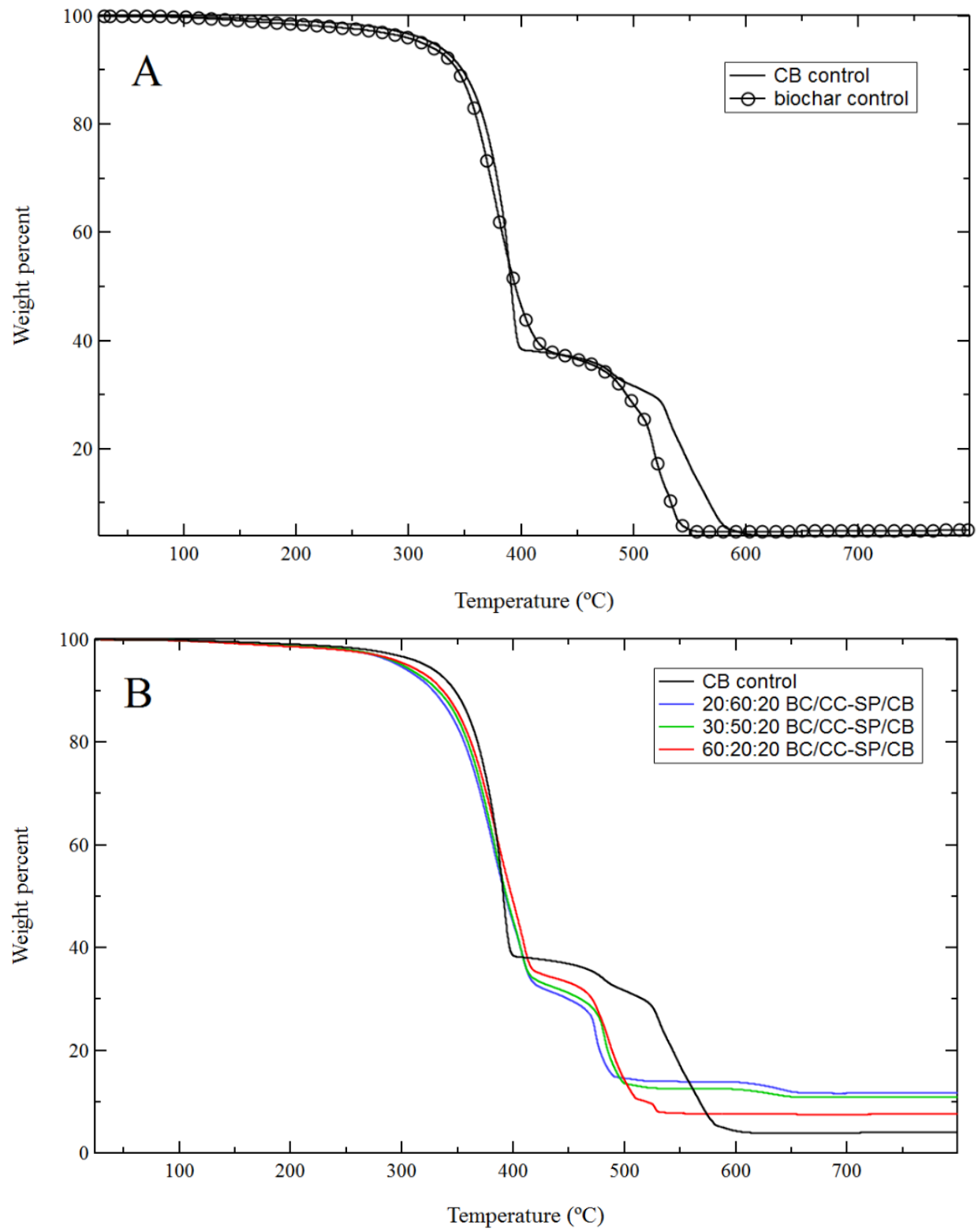

Figure 5. Cont. 


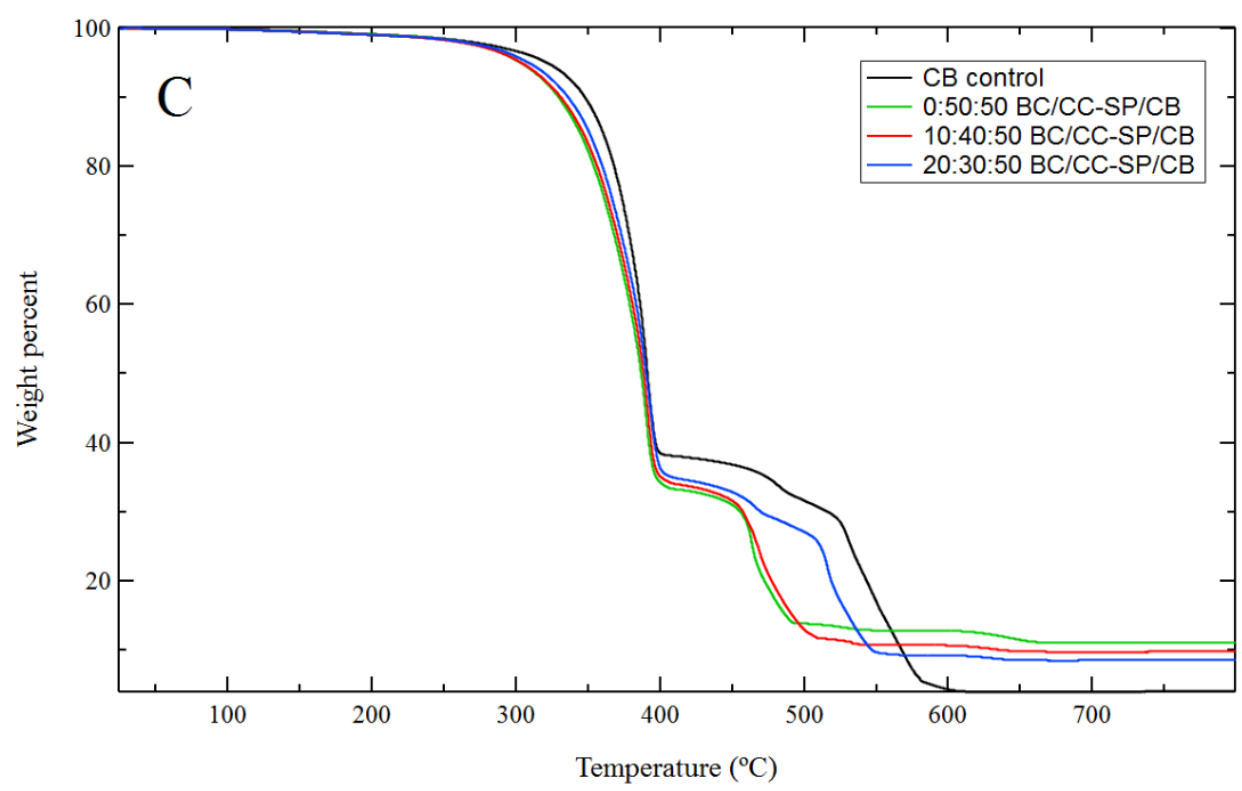

Figure 5. Thermal stability for: (A) 100\% CB filled control and 100\% silica-milled biochar, (B) composite samples with $20 \% \mathrm{CB}$ and increasing BC:CC-SP ratio, and (C) composite samples with $50 \% \mathrm{CB}$ and increasing BC:CC-SP ratio.

\section{Conclusions}

Recently a synergistic relationship between calcium carbonate, soy protein, and natural rubber was discovered, in which the reinforcement properties of calcium carbonate on natural rubber were improved with soy protein. The soy protein increased the effective crosslink density in the rubber and allowed similar mechanical performance to silicareinforced rubber. This process was simplified to remove microfluidization and drying steps by using all dry components that could be compounded directly into the rubber masterbatch mixing step, thus significantly reducing cost.

Another long-term goal of our group has been to replace carbon black with renewable biochar. In this work we tried to couple these two concepts to see if a simplified calcium carbonate-soy protein reinforcement process could yield enough improvement to increase the amount of carbon black substitution with Paulownia hardwood biochar in natural rubber, currently about $40-50 \%$ [7].

It was found that natural rubber composites with 8:32:60 and 10:40:50 ratios of biochar:CC-SP:CB had tensile strengths within experimental error of the $100 \% \mathrm{CB}$ control, along with better elongational and toughness properties. Thus $40-50 \%$ of the carbon black was replaced with renewable materials. Although this work did not significantly improve the substitution capacity of Paulownia biochar for carbon black, it provides a value-added market for soy protein. Besides the tire industry, natural rubber composite applications such as gaskets, seals, tubing and hoses would benefit from this research, and also become more sustainable.

Funding: This research was supported by the U.S. Department of Agriculture, Agricultural Research Service. Mention of trade names or commercial products in this publication is solely for the purpose of providing specific information and does not imply recommendation or endorsement by the U.S. Department of Agriculture. USDA is an equal opportunity provider and employer.

Data Availability Statement: Requests for data contained in this manuscript should be directed to the author at Steve.Peterson@usda.gov.

Acknowledgments: The author would like to thank Steve Nichols of Biochar Options for providing biochar samples (obtained in 2017); Kelly Utt for obtaining SEM images; Jason Adkins for performing TGA experiments, and A.J. Thomas for composite preparation and tensile properties, CHNO, density and ash measurements. 
Conflicts of Interest: The author declares no conflict of interest.

\section{References}

1. Sanders, I.J.; Peeten, T.L. (Eds.) Carbon Black: Production, Properties and Uses; Nova Science Publishers, Inc.: Hauppage, NY, USA, 2011.

2. Spahr, M.E.; Rothon, R. Carbon Black as a Polymer Filler. In Polymers and Polymeric Composites: A Reference Series; Palsule, S., Ed.; Springer: Berlin/Heidelberg, Germany, 2016; pp. 1-31.

3. Kuhns, R.J.; Shaw, G.H. Peak Oil and Petroleum Energy Resources. In Navigating the Energy Maze: The Transition to a Sustainable Future; Kuhns, R.J., Shaw, G.H., Eds.; Springer International Publishing: Cham, Switzerland, 2018; pp. 53-63.

4. Lee, C.-C.; Olasehinde-Williams, G.; Akadiri, S.S. Are geopolitical threats powerful enough to predict global oil price volatility? Environ. Sci. Pollut. Res. 2021, 28, 28720-28731. [CrossRef]

5. Ragothaman, A.; Anderson, W.A. Air Quality Impacts of Petroleum Refining and Petrochemical Industries. Environments 2017, 4, 66. [CrossRef]

6. Lehmann, J.; Joseph, S. Biochar for Environmental Management: Science and Technology, 2nd ed.; Routledge: New York, NY, USA, 2015; p. 976.

7. Peterson, S.C. Silica-Milled Paulownia Biochar as Partial Replacement of Carbon Black Filler in Natural Rubber. J. Compos. Sci. 2019, 3, 107. [CrossRef]

8. Mukome, F.N.D.; Zhang, X.; Silva, L.C.R.; Six, J.; Parikh, S.J. Use of Chemical and Physical Characteristics To Investigate Trends in Biochar Feedstocks. J. Agric. Food Chem. 2013, 61, 2196-2204. [CrossRef]

9. Demirbas, A. Effects of temperature and particle size on bio-char yield from pyrolysis of agricultural residues. J. Anal. Appl. Pyrol. 2004, 72, 243-248. [CrossRef]

10. Peterson, S.C.; Appell, M.; Jackson, M.A.; Boateng, A.A. Comparing corn stover and switchgrass biochar: Characterization and sorption properties. Can. J. Agric. Sci. 2013, 5, 1-8. [CrossRef]

11. Lima, I.M.; Marshall, W.E. Adsorption of selected environmentally important metals by poultry manure-based granular activated carbons. J. Chem. Technol. Biotechnol. 2005, 80, 1054-1061. [CrossRef]

12. Peterson, S.C. Utilization of low-ash biochar to partially replace carbon black in SBR composites. J. Elastomers Plast. 2013, 45, 487-497. [CrossRef]

13. Peterson, S.C.; Chandrasekaran, S.R.; Sharma, B.K. Birchwood biochar as partial carbon black replacement in styrene-butadiene rubber composites. J. Elastomers Plast. 2016, 48, 305-316. [CrossRef]

14. Gent, A.N.; Pulford, C.T.R. Micromechanics of fracture in elastomers. J. Mater. Sci. 1984, 19, 3612-3619. [CrossRef]

15. Peterson, S.C.; Kim, S. Reducing Biochar Particle Size with Nanosilica and Its Effect on Rubber Composite Reinforcement. J. Polym. Environ. 2020, 28, 317-322. [CrossRef]

16. Yadav, N.K.; Vaidya, B.N.; Henderson, K.; Lee, J.F.; Stewart, W.M.; Dhekney, S.A.; Joshee, N. A review of Paulownia biotechnology: A short rotation, fast growing multipurpose bioenergy tree. Am. J. Plant Sci. 2014, 4, 2070-2082. [CrossRef]

17. Basu, C.; Joshee, N.; Gezalian, T.; Vaidya, B.N.; Satidkit, A.; Hemmati, H.; Perry, Z.D. Cross-species PCR and field studies on Paulownia elongata: A potential bioenergy crop. Bioethanol 2016, 2, 12-23. [CrossRef]

18. Jiménez, L.; Rodríguez, A.; Ferrer, J.L.; Ṕerez, A.; Angulo, V. Paulownia, a fast-growing plant, as a raw material for paper manufacturing. Afinidad 2005, 62, 100-105.

19. Institute, W.P. Paulownia Growing Zones. Available online: http://worldpaulownia.com/growing-zones (accessed on 17 May 2021).

20. Dominguez, E.; Romani, A.; Domingues, L.; Garrote, G. Evaluation of strategies for second generation bioethanol production from fast growing biomass Paulownia within a biorefinery scheme. Appl. Energy 2017, 187, 777-789. [CrossRef]

21. Ayrilmis, N.; Kaymakci, A. Fast growing biomass as reinforcing filler in thermoplastic composites: Paulownia elongata wood. Ind. Crops Prod. 2013, 43, 457-464. [CrossRef]

22. Vaughn, S.F.; Kenar, J.A.; Tisserat, B.; Jackson, M.A.; Joshee, N.; Vaidya, B.N.; Peterson, S.C. Chemical and physical properties of Paulownia elongata biochar modified with oxidants for horticultural applications. Ind. Crops Prod. 2017, 97, 260-267. [CrossRef]

23. Jong, L. Synergistic Effect of Calcium Carbonate and Biobased Particles for Rubber Reinforcement and Comparison to Silica Reinforced Rubber. J. Compos. Sci. 2020, 4, 113. [CrossRef]

24. Peterson, S.C.; Joshee, N. Co-milled silica and coppiced wood biochars improve elongation and toughness in styrene-butadiene elastomeric composites while replacing carbon black. J. Elastomers Plast. 2018, 50, 667-676. [CrossRef]

25. Peterson, S.C. Coppiced Biochars as Partial Replacement of Carbon Black Filler in Polybutadiene/Natural Rubber Composites. J. Compos. Sci. 2020, 4, 147. [CrossRef]

26. Kiss, A.; Fekete, E.; Pukánszky, B. Aggregation of $\mathrm{CaCO}_{3}$ particles in PP composites: Effect of surface coating. Compos. Sci. Technol. 2007, 67, 1574-1583. [CrossRef]

27. Darmstadt, H.; Roy, C.; Kaliaguine, S.; Xu, G.; Auger, M.; Tuel, A.; Ramaswamy, V. Solid state 13C-NMR spectroscopy and XRD studies of commercial and pyrolytic carbon blacks. Carbon 2000, 38, 1279-1287. [CrossRef]

28. Bendit, E.G. A quantitative x-ray diffraction study of the $\alpha-\beta$ transformation in wool keratin. Text. Res. J. 1960, 30, 547-555. [CrossRef] 